\title{
Energy Dissipation Bracing Systems in Steel Frames Using FRP Composite Materials
}

\author{
Ioannis G. Raftoyiannis* \\ Department of Civil Engineering, National Technical University of Athens, Athens 15780, Greece
}

\begin{abstract}
Passively damped bracing systems in steel frames, in which the conventional materials of the joint are replaced by high damping viscoelastic materials, have the potential of being effective practical means for passive vibration control of dynamically loaded civil engineering structures. However, this potential can be realized only if the associated structural penalties are reduced within acceptable limits. This paper describes a rational methodology for the development of an advanced joining type for structural systems capable of providing enhanced dissipation of vibration energy without serious penalties in strength, stiffness, or weight characteristics. One such configuration is that of a V-type bracing system with a joint which provides a beneficial deformation coupling between the direction of load transfer and less critical offset directions. A comprehensive parametric study has been carried out in order to establish design guidelines for favorable tradeoffs between damping benefits and the associated stiffness and strength penalties in an FRP V-type joint. The results are compared with the corresponding tradeoffs for a V-type joint made from conventional materials.
\end{abstract}

\section{INTRODUCTION}

Bracing systems are commonly used in steel frames in order to resist lateral loads. Many types of bracing systems such as V, K and X-type bracings have been developed in order to comply with structural design requirements as well as architectural demands. Design guidelines for bracing systems are readily available in modern codes [1,2]. Moreover, advanced bracing systems such as eccentrically braced frames [3] and chevron-braced frames [4] have been also developed in order to resist transverse dynamic loads. Eccentrically braced frames rely on the yielding of a link beam between eccentric braces, which provides ductility and energy dissipation under dynamic loads. In a chevron-braced frame, energy dissipation solely depends on the nonlinear cyclic response of the braces. Consequently, numerous research studies have been initiated in recent years to improve the performance of bracing systems through the introduction of new structural configurations [5], the use of high performance materials [6] as well as passive energy dissipation devices such as friction [7] and viscous fluid dampers [8].

In this work, a V-type bracing system utilizing an advanced joint made from fiber-reinforced-polymer (FRP) with viscous properties is introduced. Among all the above dynamic performance improvement techniques, using viscous dampers in a structure has the unique advantage of reducing the structure base shear force and deflections at the same time since the velocity-dependent maximum viscous force is out of phase with the maximum deflection of the structure. Furthermore, the addition of an FRP joint into a steel framed structure with V-bracings alters the force-displacement relationships and thus, the dynamic modal characteristics of the structure. Consequently, FRP joints seem to be powerful

*Address correspondence to this author at the Department of Civil Engineering, National Technical University of Athens, Athens 15780, Greece; Tel: +30-210-7722454; Fax: +30-210-7722482;

E-mail: rafto@central.ntua.gr tools for improving the dynamic performance of V-braced steel frames.

Many research studies concerning the effect of V-type bracings with dampers on the dynamic performance of steel building structures have been conducted in the past [9]. However, there is no comparative research study on the dynamic performance of $\mathrm{V}$-bracing steel frames with and without FRP joints as a function of dynamic motion and damper parameters. Thus, this study focuses on comparing the dynamic performance of $\mathrm{V}$-bracing steel frames with and without FRP joints as a function of the intensity and frequency characteristics of the dynamic motion as well as the damping ratio and velocity exponent of the FRP material. The results from such a research study may then be used to measure the efficiency of FRP joints for improving the dynamic performance of V-bracing systems as a function of the ground motion characteristics and their parameters and arrive at important decisions related to the dynamic retrofitting and design of V-bracing steel frames using advanced FRP joints.

In typical V-braced frames, the beams are incapable of performing as a ductile link for the steel bracing system that is inserted in the frame bays. A vertical steel shear link can be introduced forming a Y-bracing pattern. In this case, the vertical shear link can be attached to the beam of the steel frame. Special consideration should be given to the connection between the vertical shear link and the beam. This connection, though, should have sufficient capacity to ensure effective transmission of forces when subjected transverse loads. In this work, details of a proposed link connection of an FRP-steel bracing system inserted in the bays of a steel frame are presented. The link connection is located at midspan of the steel girder and is attached to its bottom flange. The bracing forces are transmitted to the girder through an FRP plate-frame system. The proposed link connection has not yet been subjected to testing but is expected to provide the fixation to the link end as has been modeled in the analysis.

2008 Bentham Open 


\section{FRP-JOINT STIFFNESS PROPERTIES}

The joint presented herein consists from an FRP plate with thickness $t$ and dimensions $a$ and $b$. The FRP plate is bolted into a steel frame consisting from pairs of unequal-leg angle-sections connected with hinges at all 4 corners that is attached to the bottom flange of the girder at its mid-length. The braces are rigidly connected to the joint frame with welding. In Fig. (1), one can see the details of the proposed FRP plate-frame system. Since the dimensions of the frame are relatively small, the flanges of the angle sections are expected to provide enough transverse stiffness to the system, thus preventing out-of-plane instability of the FRP plateframe system. Out-of-plane buckling of the braces alone can be prevented through special considerations provided in the codes $[1,2]$
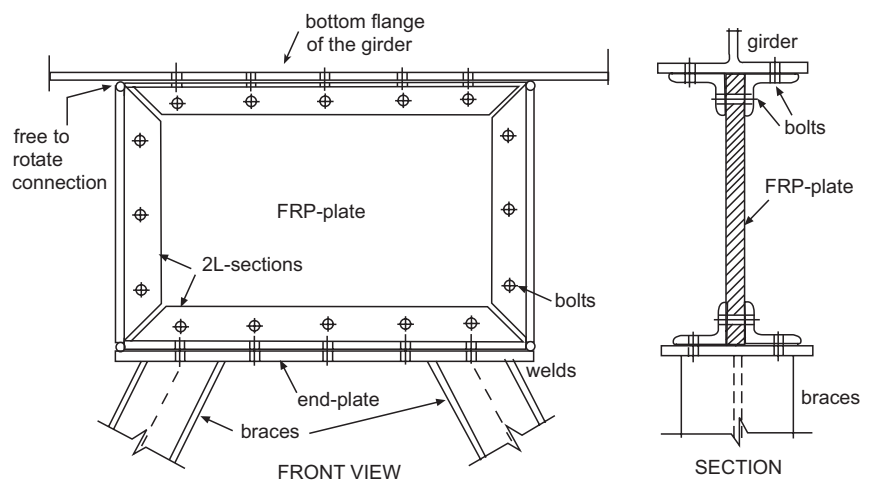

Fig. (1). Details of proposed FRP plate-frame system.

As a consequence, the FRP-joint plate is subjected to membrane forces. Composite plates are usually thin-walled with a maximum total thickness in the order of $2.0 \mathrm{~cm}$ and are produced with various cross-sectional dimensions and lay-ups. In the present case, the hand lay-up procedure is employed to produce the FRP plate with the desired properties. Two cases of laminates are considered herein for the plate: $\left[(0 / 90)_{n}\right]_{S}$ and $\left[( \pm 45)_{n}\right]_{S}$ orientation angles with respect to the horizontal direction forming a symmetric cross-ply (soft) or angle-ply (stiff) laminate, respectively. The plate consists of an even number (total $4 \mathrm{n}$ ) of E-glass/Epoxy layers. All layers have a constant fiber volume fraction $\mathrm{v}_{\mathrm{f}}=65 \%$. The material properties for all layers are $\mathrm{E}_{1}=42.3 \mathrm{GPa}$, $\mathrm{E}_{2}=12.4 \mathrm{GPa}, v_{12}=0.24$ and $\mathrm{G}_{12}=6.2 \mathrm{GPa}$, where 1 denotes the fiber direction and 2 the transverse direction. Using the Classical Lamination Theory [10], the stiffness components of a generally orthotropic plate can be determined. The constitutive equation for such a laminate is

$$
\left\{\begin{array}{c}
N_{x} \\
N_{y} \\
N_{x y}
\end{array}\right\}=\left[\begin{array}{lll}
A_{11} & A_{12} & A_{16} \\
A_{12} & A_{22} & A_{26} \\
A_{16} & A_{26} & A_{66}
\end{array}\right]\left\{\begin{array}{c}
\varepsilon_{x} \\
\varepsilon_{y} \\
\gamma_{x y}
\end{array}\right\}
$$

where $\{\mathrm{N}\}$ are the membrane forces (also called stress resultants) and $\{\varepsilon\}$ are the corresponding strains. The membrane stiffness coefficients $A_{i j}$ can be determined from the following relation

$$
\mathrm{A}_{\mathrm{ij}}=\int_{-\mathrm{t} / 2}^{\mathrm{t} / 2} \overline{\mathrm{Q}}_{\mathrm{ij}} \mathrm{dz}
$$

where $t$ is the laminate thickness and the terms $\bar{Q}_{i j}$ are the transformed layer stiffness components. The terms $\bar{Q}_{i j}$ for various values of the lamination angle $\theta$ are listed in Table 1 . Inverting eq(1) we obtain

$$
\left\{\begin{array}{c}
\varepsilon_{\mathrm{x}} \\
\varepsilon_{\mathrm{y}} \\
\gamma_{\mathrm{xy}}
\end{array}\right\}=\left[\begin{array}{lll}
\mathrm{a}_{11} & \mathrm{a}_{12} & \mathrm{a}_{16} \\
\mathrm{a}_{12} & \mathrm{a}_{22} & \mathrm{a}_{26} \\
\mathrm{a}_{16} & \mathrm{a}_{26} & \mathrm{a}_{66}
\end{array}\right]\left\{\begin{array}{c}
\mathrm{N}_{\mathrm{x}} \\
\mathrm{N}_{\mathrm{y}} \\
\mathrm{N}_{\mathrm{xy}}
\end{array}\right\}
$$

Table 1. Transformed stiffness $\overline{\mathrm{Q}}_{\mathrm{ij}}(\mathrm{GPa})$ for various $\theta$

\begin{tabular}{|c|c|c|c|c|c|c|}
\hline$\theta$ & $\overline{\mathrm{Q}}_{11}$ & $\overline{\mathrm{Q}}_{22}$ & $\overline{\mathrm{Q}}_{12}$ & $\overline{\mathrm{Q}}_{66}$ & $\overline{\mathrm{Q}}_{16}$ & $\overline{\mathrm{Q}}_{26}$ \\
\hline 0 & 43.03 & 12.61 & 3.03 & 6.20 & 0 & 0 \\
\hline 90 & 12.61 & 43.03 & 3.03 & 6,20 & 0 & 0 \\
\hline 45 & 21.62 & 21.62 & 9.22 & 12.40 & 7.60 & 7.60 \\
\hline-45 & 21.62 & 21.62 & 9.22 & 12.40 & -7.60 & -7.60 \\
\hline
\end{tabular}

Notice that although the shear-extension coupling terms $A_{16}$ and $A_{26}$ in eq(1) vanish in symmetric (balanced) laminates, the term $a_{11}$ in eq(3) includes the shear effect due to layer stiffness transformation. The terms $\mathrm{a}_{16}$ and $\mathrm{a}_{26}$ are also zero in this case. The effective longitudinal, transverse and shear moduli $\mathrm{E}_{\mathrm{x}}, \mathrm{E}_{\mathrm{y}}, \mathrm{G}_{\mathrm{xy}}$ as well as the effective Poisson's ratio $v_{\mathrm{xy}}$ can be calculated from eq(4) as following

$$
\begin{aligned}
& E_{x}=\frac{1}{a_{11} t}, \quad E_{y}=\frac{1}{a_{22} t}, \\
& v_{x y}=-\frac{a_{12}}{a_{22}}, \quad G_{x y}=\frac{1}{a_{66} t}
\end{aligned}
$$

The effective moduli $E_{x}, E_{y}, v_{x y}, G_{x y}$ are also listed in Table 2 for both cross-ply $\left[(0 / 90)_{n}\right]_{S}$ (soft) and angle-ply $\left[( \pm 45)_{\mathrm{n}}\right]_{\mathrm{S}}$ (stiff) balanced laminates.

Table 2. Effective properties for various laminates

\begin{tabular}{|c|c|c|c|c|}
\hline Lay-ups & $\begin{array}{c}\mathbf{E}_{\mathbf{x}} \\
(\mathbf{G P a})\end{array}$ & $\begin{array}{c}\mathbf{E}_{\mathbf{y}} \\
(\mathbf{G P a})\end{array}$ & $\begin{array}{c}\boldsymbol{v}_{\mathbf{x y}} \\
-\end{array}$ & $\begin{array}{c}\mathbf{G}_{\mathbf{x y}} \\
(\mathbf{G P a})\end{array}$ \\
\hline \hline$\left[(0 / 90)_{\mathrm{n}}\right]_{\mathrm{s}}$ & 27.49 & 27.49 & 0.11 & 6.20 \\
\hline$\left[( \pm 45)_{\mathrm{n}}\right]_{\mathrm{s}}$ & 17.69 & 17.69 & 0.43 & 12.40 \\
\hline
\end{tabular}

\section{V-JOINT DAMPING PROPERTIES}

The model employed is based on an elastic stress analysis rather than the viscoelastic behavior of the material. Besides elastic strength and stiffness, the model can predict only the relative energy dissipation with respect to variations in geometric parameters and stiffness ratio between the FRP material and the joint frame. The material loss factor is not in- 
cluded explicitly in the model, but it is not expected to change the predicted effects of the given design parameters on the overall joint damping, since it is not affected by either the geometry or the elastic stiffness of the joint components. For a given viscoelastic material, the loss factor may be regarded as a material property that is independent of the joint configuration and determines the actual level of dissipated energy when multiplied by the corresponding values of relative energy dissipation provided by this analysis. The underlying assumptions of the present approach are that the joint is subjected to oscillatory loading and that the viscoelastic material behaves similarly to a Voigt solid at all frequencies. solid is

The governing equation for shear deformation of such a $\tau=\mathrm{k}_{1} \gamma+\mathrm{k}_{2} \dot{\gamma}$

For the particular case of oscillatory loading, eq(5) implies that if the shear strain is described by the equation

$\gamma=\gamma_{0} \mathrm{e}^{\mathrm{i} \omega \mathrm{t}}$

then the associated shear stress can be expressed as

$\tau=\tau_{0} \mathrm{e}^{\mathrm{i} \omega \mathrm{t}}$

The stress amplitude can be directly related to the strain amplitude by substituting eqs (6) and (7) into eq(5):

$\tau_{0}=\mathrm{G}_{\mathrm{a}}(\omega) \gamma_{0}$

where $G_{a}(\omega)$ is a complex shear modulus that is related to the constants $\mathrm{k}_{1}$ and $\mathrm{k}_{2}$ as follows:

$\mathrm{G}_{\mathrm{a}}(\omega)=\mathrm{k}_{1}+\mathrm{i} \mathrm{k}_{2} \omega$

Usually, the complex modulus is expressed in the form

$\mathrm{G}_{\mathrm{a}}(\omega)=\mathrm{G}_{1}(\omega)+\mathrm{iG}_{2}(\omega)$

or

$\mathrm{G}_{\mathrm{a}}(\omega)=\mathrm{G}_{1}(\omega)[1+\mathrm{i} \eta(\omega)]$

where $\mathrm{G}_{1}$ and $\mathrm{G}_{2}$ are storage and dissipation moduli, respectively, whereas $\eta$ is the material loss factor, which is defined as

$\eta(\omega)=\frac{G_{2}(\omega)}{G_{1}(\omega)}$

When inertia effects are ignored, the complex modulus representation leads to a quasi-static analysis, in which the material properties may change with frequency or temperature variation, but the form of the governing elasticity equations remains unchanged. The quasi-static nature of the model is reflected implicitly in these equations, since the oscillatory quantities are represented by their amplitudes. However, their complete time variations must be considered explicitly in order to evaluate the total amount of mechanical energy D dissipated per cycle by the viscoelastic material (Flügge [11]):

$$
\mathrm{D}=\int_{\mathrm{V}_{\mathrm{a}}} \oint \tau(\mathrm{t}) \dot{\gamma}(\mathrm{t}) \mathrm{dt} d \mathrm{v}
$$

where $\mathrm{V}_{\mathrm{a}}$ is the volume of the FRP material.
The shear strain variation in eq(6) can be written as

$\gamma(t)=\gamma_{0}[\cos (\omega t)+i \sin (\omega t)]$

The corresponding time history of the associated shear stress is obtained by substituting eq(14) into eq(5) and expressing the constants $k_{1}$ and $k_{2}$ in terms of the moduli $G_{1}$ and $\mathrm{G}_{2}$

$$
\begin{aligned}
\tau(t)=\gamma_{0}\left\{G_{1} \cos (\omega t)-G_{2} \sin (\omega t)+\right. \\
\left.+i \gamma_{0}\left[G_{1} \sin (\omega t)+G_{2} \cos (\omega t)\right]\right\}
\end{aligned}
$$

As pointed out by Flügge [11], only the real components of eqs(14) and (15) must be substituted into eq(13) since the dissipated energy $\mathrm{D}$ represents the work done by the stress on a deformation that is $90^{\circ}$ out of phase with it. The total work done during the cycle by the in-phase components of stress and strain is equal to zero since it corresponds to elastic behavior.

After the time integration in eq(13) is carried out from $\mathrm{t}=0$ to $\mathrm{t}=2 \pi / \omega$, the dissipated energy $\mathrm{D}$ can be expressed as

$$
\mathrm{D}=\pi \mathrm{G}_{1} \eta \int_{\mathrm{V}_{\mathrm{a}}} \gamma_{0}^{2} \mathrm{dv}
$$

The magnitude of the complex shear strain $\gamma_{0}$ in the viscoelastic material is, therefore, required for the evaluation of D. If the FRP material is assumed to be the only source of energy dissipation in a passively damped joint, the parameter $\mathrm{D}$ is a direct measure of the overall joint damping. Equation (16) shows that for a given viscoelastic material at given frequency and temperature conditions, the damping characteristics are determined by the magnitude of shear strains induced in the material.

This discussion supports the approach of employing a fully elastic model in order to evaluate the effect of structural interactions between the constituents of a passively damped joint on the amount of energy dissipated by its viscoelastic material. For a certain loss factor of the viscoelastic material, the joint damping may be considered to be proportional to the elastic distortional (octahedral) energy stored in the material during a loading cycle. If the plane stress assumption is adopted for the stress analysis of the present joint configuration, this energy [12] is expressed as

$$
\begin{aligned}
U_{d}=\frac{1}{12 G_{1}} \int_{V_{a}}\left[\left(\sigma_{x}-\sigma_{y}\right)^{2}+\right. \\
\left.+\sigma_{y}^{2}+\sigma_{x}^{2}+6 \tau_{x y}^{2}\right] d v
\end{aligned}
$$

where the stress components in eq(17) correspond to the amplitude of the external oscillatory load of the joint. The damping assessment in the present work relies, therefore, on the approximation

$\mathrm{D} \approx \mathrm{C} \cdot \mathrm{U}_{\mathrm{d}}$

where $\mathrm{C}$ is a proportionality constant that depends on the loss factor of the viscoelastic material. The above procedure can be employed to obtain the damping ratio. In the FRP cases studied herein a damping ratio $\mathrm{c}^{*}=10 \%$ shall be considered. 


\section{V-BRACED FRAME MODELS}

Let us consider a simple frame ABCDE made from structural steel with a conventional V-type bracing system (see Fig. 2). Taking into account that the axial deformation of the bar BCD is negligibly small, the horizontal force $\mathrm{F}$ due to earthquake or wind actions can be assumed acting on the girder at the point $\mathrm{C}$ lying on top of the $\mathrm{V}$-joint without loss of generality. Since the joint is rigid, the loads are partially transferred to the columns and mainly to the bracing system. This implies that the structural system can be treated as a single degree-of-freedom system. The total lateral stiffness of the braced frame $\mathrm{K}_{1}$ can be determined by simply superimposing the stiffness of the unbraced frame $\mathrm{K}_{\mathrm{f}}$ and the contribution of the bracings $\mathrm{K}_{\mathrm{b}}$. Hence,

$\mathrm{K}_{1}=\mathrm{K}_{\mathrm{f}}+\mathrm{K}_{\mathrm{b}}$

Thus, the force-displacement relation for the conventionally braced frame is

$\mathrm{F}=\mathrm{K}_{1} \delta_{1}$

where $\delta_{1}$ is the horizontal displacement of the girder. The equation of motion is readily obtained [13]

$M \ddot{\delta}_{1}+K_{1} \delta_{1}=F(t)$

where $\mathrm{M}$ is the total mass of the girder.

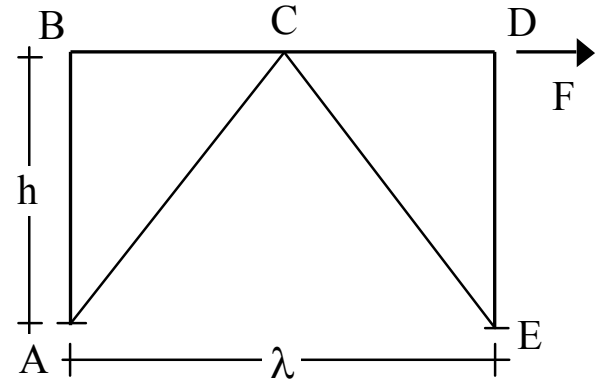

Fig. (2). Conventionally V-braced frame.

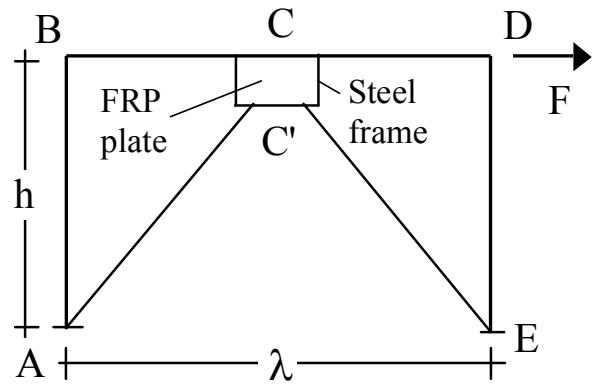

Fig. (3). Composite FRP V-braced frame.

Consider next the same steel frame, where the joint $\mathrm{C}$ is constructed using an FRP laminated plate with dimensions a and $b$ placed into a steel frame as shown in Fig. (3). When the frame is loaded with the horizontal force $\mathrm{F}$ applied to the girder, and since the stiffness of the bracings is much higher than the stiffness of the frame, the composite plate is subjected to in-plane stressing due to the horizontal movement of the girder and the tensile and compressive deformation of the bracing members. In the horizontal direction, the latter cancel each other due to symmetry, and thus, the FRP plate is deformed purely due to shear, i.e. the top edge (point C) moves relatively to the bottom edge (point $\mathrm{C}^{\prime}$ ) by a distance $\delta_{0}$ (see Fig. 4).

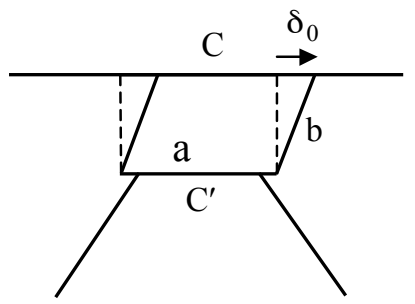

Fig. (4). Deformed configuration of the FRP V-joint.

In order to confirm the deformed configuration of the joint shown in Fig. (4), a finite element analysis has been performed on a full-scale frame model with braces and an FRP plate. The frame is subjected to a horizontal static load and the deformed configuration along with the membrane shear stress resultants $\mathrm{N}_{\mathrm{xy}}$ are shown in Fig. (5). One can clearly see that the FRP plate is deformed as shown in Fig. (4) and that the shearing stresses developing are constant throughout the plate.

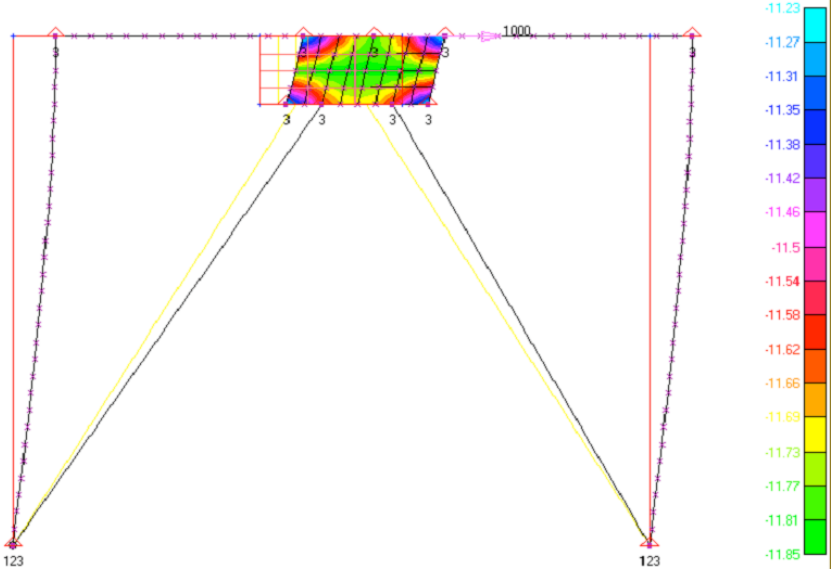

Fig. (5). Finite element model of an FRP V-joint frame.

The force-displacement relation for the composite plate can be determined from the following expression

$\mathrm{T}=\left(\frac{\mathrm{a}}{\mathrm{b}} \frac{1}{\mathrm{a}_{66}}\right) \delta_{0}=\left(\frac{\mathrm{a}}{\mathrm{b}} \mathrm{G}_{\mathrm{xy}} \mathrm{t}\right) \delta_{0}=\mathrm{K}_{\mathrm{c}} \delta_{0}$

where $\mathrm{T}$ is the total shearing force and $\mathrm{a}_{66}$ is the shearing compliance of the laminate plate. It is obvious that the system has now an additional degree-of-freedom, thus becoming a 2-DOF system $\left(\delta_{2}=\delta_{1}-\delta_{0}\right)$.

The equivalent 2-DOF mechanical system is shown in Fig. (6). 


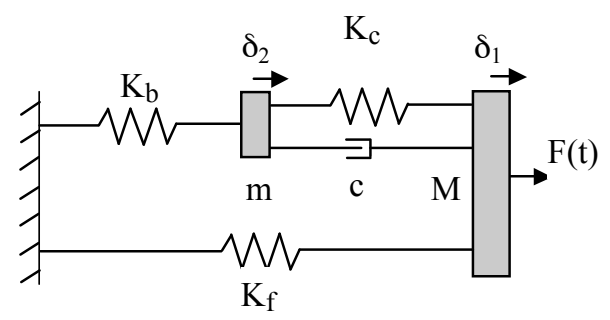

Fig. (6). Equivalent 2-DOF system of the frame.

The equations of motion for the 2-DOF system are derived as follows

$$
\begin{aligned}
{\left[\begin{array}{cr}
\mathrm{M} & 0 \\
0 & \mathrm{~m}
\end{array}\right]\left\{\begin{array}{l}
\ddot{\delta}_{1} \\
\ddot{\delta}_{2}
\end{array}\right\}+\left[\begin{array}{cc}
\mathrm{c} & -\mathrm{c} \\
-\mathrm{c} & \mathrm{c}
\end{array}\right]\left\{\begin{array}{l}
\dot{\delta}_{1} \\
\dot{\delta}_{2}
\end{array}\right\}+} \\
+\left[\begin{array}{cc}
\mathrm{K}_{\mathrm{f}}+\mathrm{K}_{\mathrm{c}} & -\mathrm{K}_{\mathrm{c}} \\
-\mathrm{K}_{\mathrm{c}} & \mathrm{K}_{\mathrm{c}}+\mathrm{K}_{\mathrm{b}}
\end{array}\right]\left\{\begin{array}{c}
\delta_{1} \\
\delta_{2}
\end{array}\right\}=\left\{\begin{array}{c}
\mathrm{F}(\mathrm{t}) \\
0
\end{array}\right\}
\end{aligned}
$$

where $\delta_{1}$ and $\delta_{2}$ are the total displacements of $\mathrm{C}$ and $\mathrm{C}^{\prime}, \mathrm{M}$ is the vibrating mass of the beam, $\mathrm{m}$ is the lumped mass of the bracing system at point $\mathrm{C}^{\prime}$, and $\mathrm{c}$ is the damping coefficient of the FRP joint. Notice that damping is ignored for the steel members of the frame, thus the present FRP-joint forms an internal damping system.

In order to facilitate a parametric study, the following non-dimensional quantities are introduced into eqs (24):

$$
\left.\begin{array}{ll}
\mathrm{f}=\frac{\mathrm{F}}{\mathrm{K}_{\mathrm{f}} \ell}, & \mathrm{t}^{*}=\sqrt{\frac{\mathrm{K}_{\mathrm{f}}}{\mathrm{M}} \mathrm{t},} \\
\mathrm{m}^{*}=\mathrm{m} / \mathrm{M}, & \mathrm{c}^{*}=\mathrm{c} / \sqrt{\mathrm{K}_{\mathrm{f}} \mathrm{M}}, \\
\mathrm{K}_{\mathrm{c}}^{*}=\mathrm{K}_{\mathrm{c}} / \mathrm{K}_{\mathrm{f}}, & \mathrm{K}_{\mathrm{b}}^{*}=\mathrm{K}_{\mathrm{b}} / \mathrm{K}_{\mathrm{f}}
\end{array}\right\}
$$

Displacement and traction continuity conditions are imposed in all directions along the FRP material - joint frame interfaces so that no debonding and microslip effects are included in this investigation.

\section{NUMERICAL RESULTS}

The $\mathrm{V}$-joint presented herein leads to a reduced overall stiffness $\mathrm{K}_{2}$ for the frame, which is

$\mathrm{K}_{2}=\mathrm{K}_{\mathrm{f}}+\frac{1}{\frac{1}{\mathrm{~K}_{\mathrm{b}}}+\frac{1}{\mathrm{~K}_{\mathrm{c}}}}$

Thus, in the case of the conventionally braced frame the corresponding eigenfrequency $\omega_{1}$ is

$\omega_{1}=\sqrt{\mathrm{K}_{1} / \mathrm{M}}$

while for the FRP jointed frame, the corresponding eigenfrequency $\omega_{2}$ is

$\omega_{2}=\sqrt{\mathrm{K}_{2} / \mathrm{M}}$

In Fig. (7), one can see the variation of the stiffness ratio $\mathrm{K}_{2} / \mathrm{K}_{1}$ with respect to the non-dimensional FRP plate stiff- ness $\mathrm{K}_{\mathrm{c}}^{*}$, while in Fig. (8), the variation of the fundamental period ratio $T_{2} / T_{1}$ is plotted against the FRP plate stiffness $\mathrm{K}_{\mathrm{c}}^{*}$.

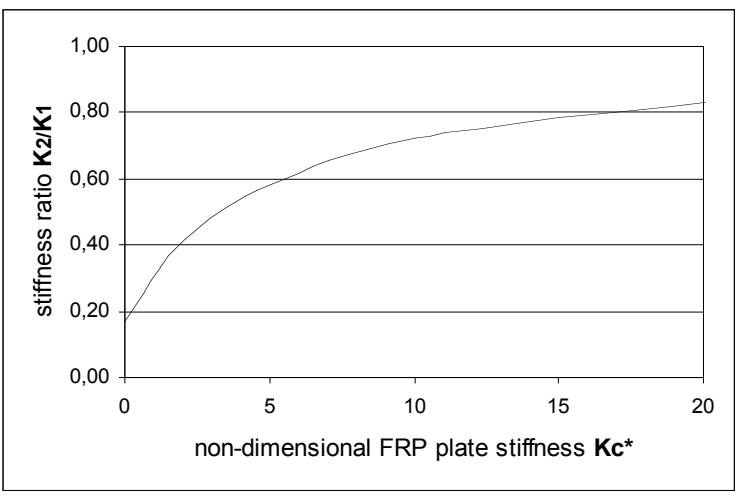

Fig. (7). Frame stiffness ratio $K_{2} / K_{1}$ with versus $K_{c}^{*}$.

The frames shown in Figs. (2) and (3) are subjected to dynamic loading acting onto the girder. Three cases of loading are considered herein: a) a step load, b) a half-sine pulse load, and c) a sinusoidal load with four cycles as shown in Fig. (9).

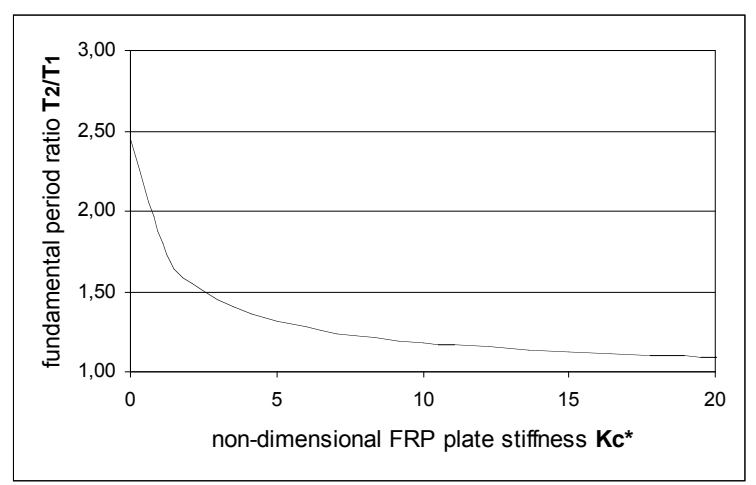

Fig. (8). Fundamental period ratio $T_{2} / T_{1}$ versus $K_{c}^{*}$.

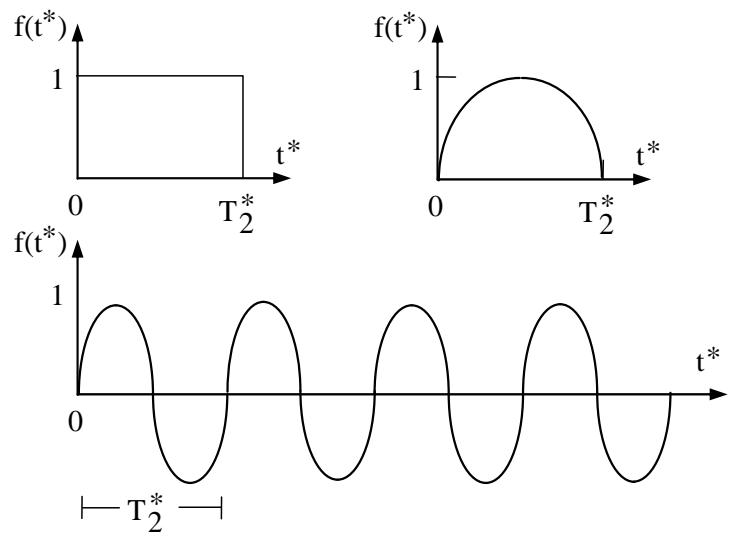

Fig. (9). Step, half-sine pulse, and sinusoidal loading.

In Fig. (10) one can see the response of a conventionally $\mathrm{V}$-braced frame with stiffness ratio $\mathrm{K}_{\mathrm{b}}^{*}=5$ under step loading with finite duration $\mathrm{t}^{*}=\mathrm{T}_{2}{ }^{*}=2 \pi / \omega_{2}$. In Fig. (11), the response 
of the same frame with a stiff plate FRP bracing system under step loading with stiffness ratios $\mathrm{K}_{\mathrm{b}}^{*}=5, \mathrm{~K}_{\mathrm{c}}^{*}=10$ (i.e. $\mathrm{K}_{2} / \mathrm{K}_{1}=0.7222, \mathrm{~T}_{2} / \mathrm{T}_{1}=1.1767$ ) and a high damping ratio $\mathrm{c}^{*}=10 \%$ is shown, where the continuous line corresponds to amplitude $\delta_{1}$ while the dashed line to amplitude $\delta_{2}$.

In Fig. (12) one can see the time variation of the shearing deformation $\delta_{0}$ of the FRP-plate.

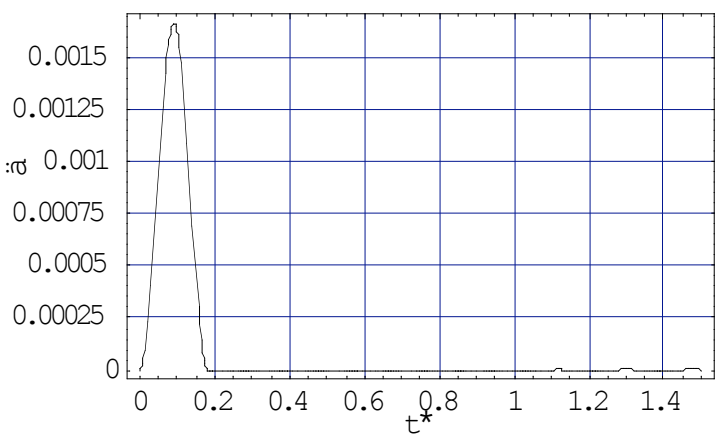

Fig. (10). Response of a conventionally-braced frame with $\mathrm{K}_{\mathrm{b}}^{*}=5$ under step loading.

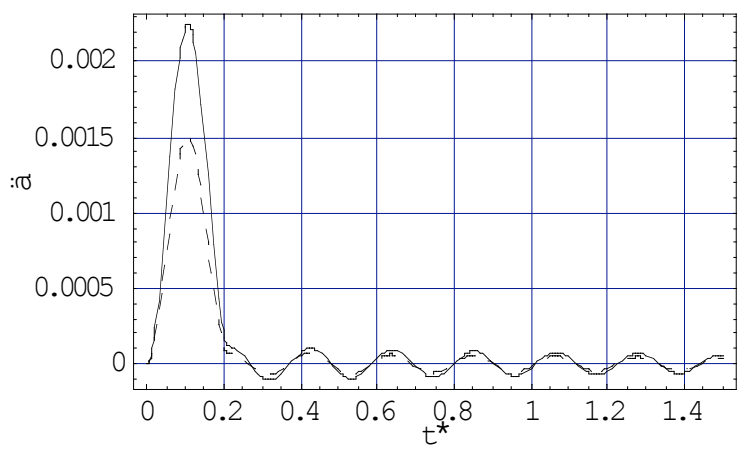

Fig. (11). Response of an FRP braced frame with $\mathrm{K}_{\mathrm{b}}^{*}=5$ and $\mathrm{K}_{\mathrm{c}}^{*}=10$ (stiff FRP plate) under step loading.

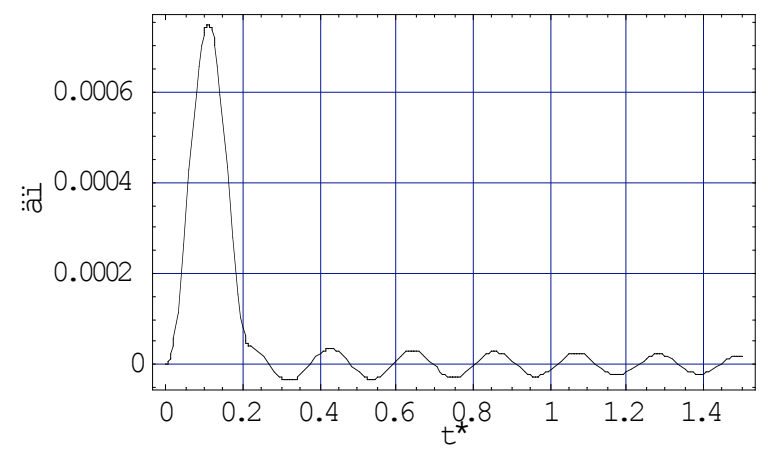

Fig. (12). Shearing deformation $\delta_{0}$ of a stiff FRP plate in a braced frame with $\mathrm{K}_{\mathrm{b}}^{*}=5, \mathrm{~K}_{\mathrm{c}}^{*}=10$ versus time $\mathrm{t}^{*}$.

In Fig. (13) one can see the response of a frame with a soft FRP-plate bracing system and stiffness ratios $\mathrm{K}_{\mathrm{b}}^{*}=5$, $\mathrm{K}_{\mathrm{c}}^{*}=5$ (i.e. $\mathrm{K}_{2} / \mathrm{K}_{1}=0.583, \mathrm{~T}_{2} / \mathrm{T}_{1}=1.309$ ) under step loading, while in Fig. (14) the time variation of the shearing force $\mathrm{T}$ of the FRP-plate is shown.

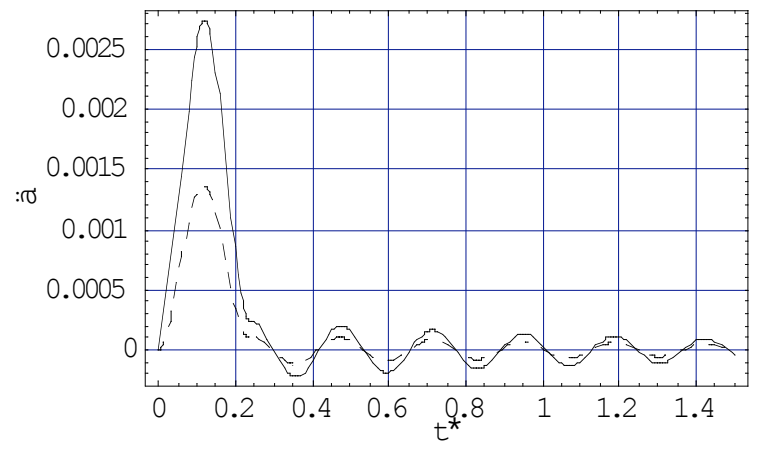

Fig. (13). Response of an FRP braced frame with $\mathrm{K}_{\mathrm{b}}^{*}=5$ and $\mathrm{K}_{\mathrm{c}}^{*}=5$ (soft FRP plate).

From a comparison of the system responses shown in Figs. (10) and (11) (stiff FRP plate) and in Figs. (10) and (13) (soft FRP plate) it can be seen that the transverse stiffness drops almost $27,8 \%$ and the corresponding fundamental period rises about $17,6 \%$ when a stiff FRP plate is used, while in the case of a soft FRP plate the corresponding stiffness drops almost $41,9 \%$ and the corresponding fundamental period rises about $30,9 \%$.

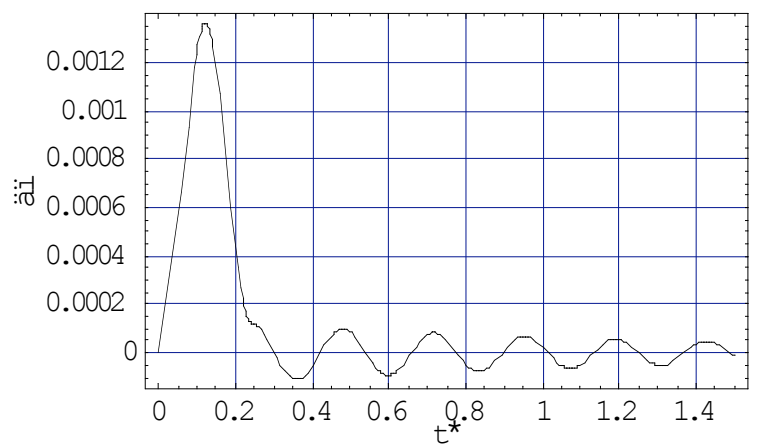

Fig. (14). Shearing deformation $\delta_{0}$ of a soft FRP plate in a braced frame with $\mathrm{K}_{\mathrm{b}}^{*}=\mathrm{K}_{\mathrm{c}}^{*}=5$ versus time $\mathrm{t}^{*}$.

Moreover, the maximum amplitude $\delta_{1}$ of the frame is $32.3 \%$ higher in the case of a stiff FRP plate, while the rise in amplitude is $58.8 \%$ for a soft FRP plate compared to the maximum amplitude $\delta_{1}$ of the conventionally braced frame. Contrarily, the maximum axial force $\mathrm{N}_{\mathrm{br}}$ of the braces drops in absolute values almost $25.3 \%$ in the case of a stiff FRP plate and $37.1 \%$ in the case of a stiff FRP plate V-joint compared to the corresponding one of the conventionally braced frame.

Comparing the maximum values of the shearing deformation $\delta_{0}$ for the stiff and soft FRP plates shown in Figs. (12) and (13), it can be seen that as the stiffness of the FRP plate rises, the corresponding shearing deformation drops advertently.

Consider next, the above frame systems subjected to a half-sine load. In Fig. (15) one can see the response of a conventionally $\mathrm{V}$-braced frame with stiffness ratio $\mathrm{K}_{\mathrm{b}}^{*}=5$ under half-sine loading. In Fig. (16), the response of the same 
same frame with a stiff-plate FRP bracing system and stiffness ratios $\mathrm{K}_{\mathrm{b}}^{*}=5, \mathrm{~K}_{\mathrm{c}}^{*}=10$ under the same loading is shown.

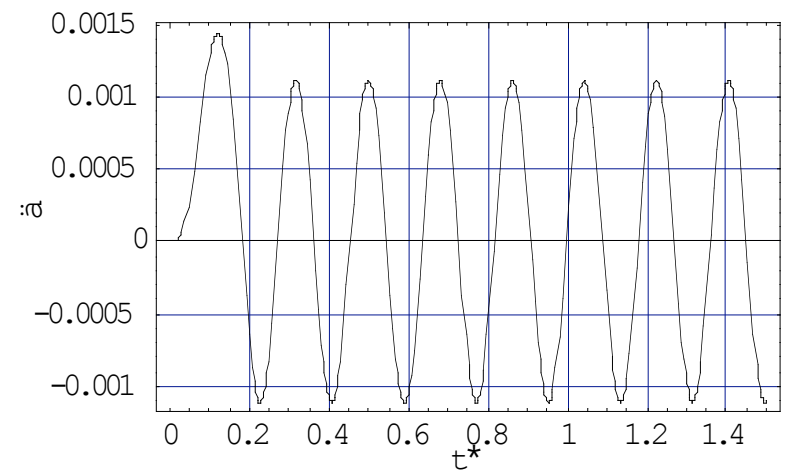

Fig. (15). Response of a conventionally-braced frame with $\mathrm{K}_{\mathrm{b}}^{*}=5$ under half-sine loading.

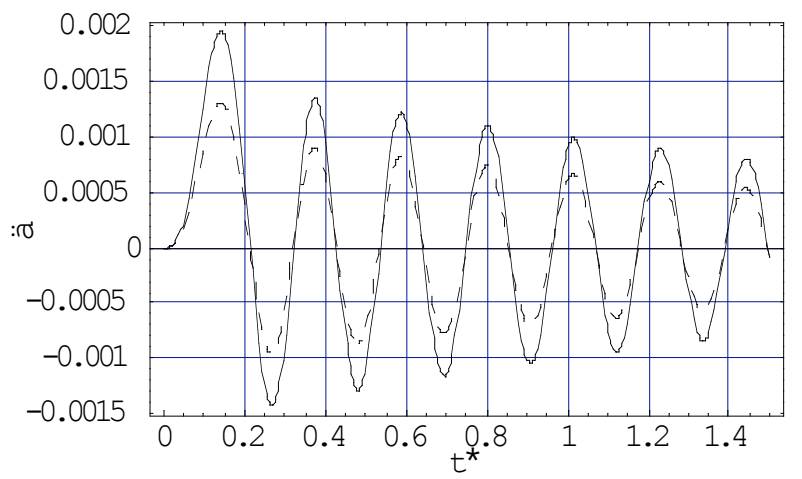

Fig. (16). Response of an FRP braced frame with $\mathrm{K}_{\mathrm{b}}^{*}=5$ and $\mathrm{K}_{\mathrm{c}}^{*}=10$ (stiff plate) under half-sine loading.

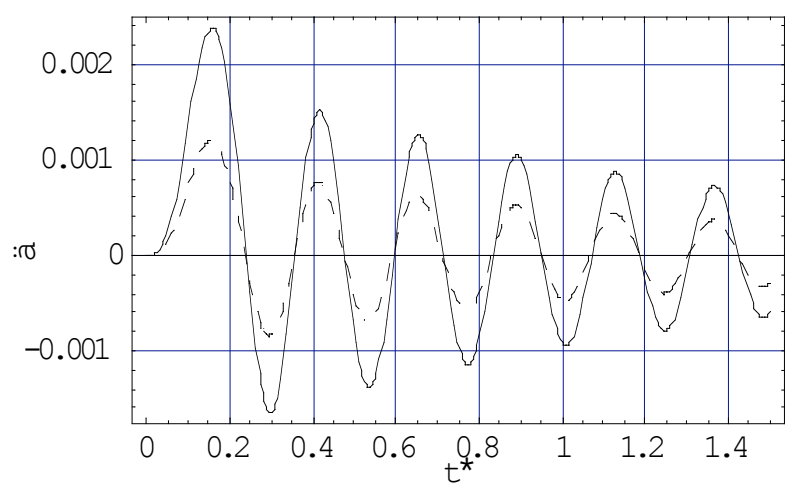

Fig. (17). Response of an FRP braced frame with $\mathrm{K}_{\mathrm{b}}^{*}=5$ and $\mathrm{K}_{\mathrm{c}}^{*}=5$ (soft plate) under half-sine loading.

In Fig. (17) one can see the response of a frame with a soft FRP-plate bracing system and stiffness ratios $\mathrm{K}_{\mathrm{b}}^{*}=5$, $\mathrm{K}_{\mathrm{c}}^{*}=5$ under half-sine loading.

From a comparison of the system responses shown in Figs. (15) and (16) (stiff FRP plate) and in Figs. (15) and (17) (soft FRP plate) it can be seen that the maximum ampli- tude $\delta_{1}$ of the frame is $35,7 \%$ higher in the case of a stiff FRP plate, while the rise in amplitude is almost $71.4 \%$ for a soft FRP plate compared to the maximum amplitude $\delta_{1}$ of the conventionally braced frame. Moreover, the maximum axial force $\mathrm{N}_{\mathrm{br}}$ of the braces drops in absolute values almost $12.0 \%$ in the case of a stiff FRP plate and $16.6 \%$ in the case of a stiff FRP plate $\mathrm{V}$-joint compared to the corresponding one of the conventionally braced frame. Note also that for time $\mathrm{t}^{*}>\mathrm{T}_{2}{ }^{*}$ the conventional (undamped) system continues to vibrate freely with constant amplitude (see Fig. 14), while the amplitude of the FRP-joint system (with internal damping) decays rapidly as shown in Figs. (16) and (17).

We finally consider the above frames subjected to a sinusoidal loading with four cycles that resembles a seismic excitation. In Fig. (18), the response of a conventionally Vbraced frame with stiffness ratio $\mathrm{K}_{\mathrm{b}}^{*}=5$ is shown, while in Fig. (19), one can see the response of the same frame with a stiff-plate FRP bracing system and stiffness ratios $\mathrm{K}_{\mathrm{b}}^{*}=5$, $\mathrm{K}_{\mathrm{c}}^{*}=10$ under the same loading.

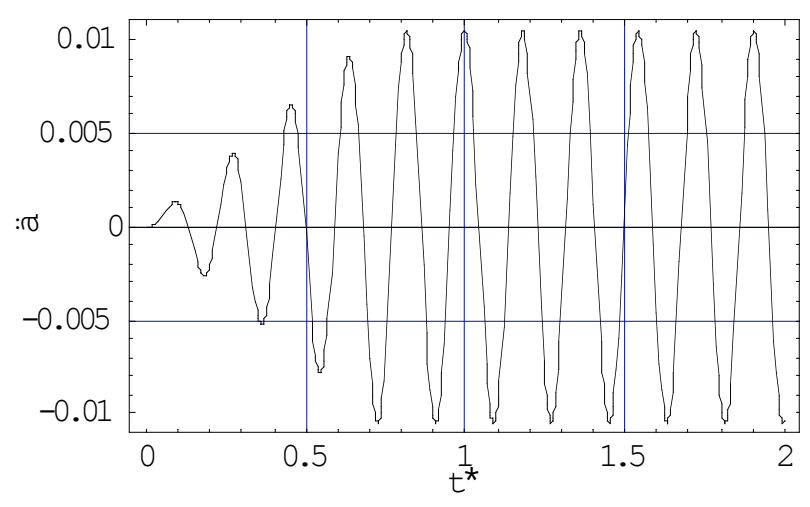

Fig. (18). Response of a conventionally-braced frame with $\mathrm{K}_{\mathrm{b}}^{*}=5$ under sinusoidal loading.

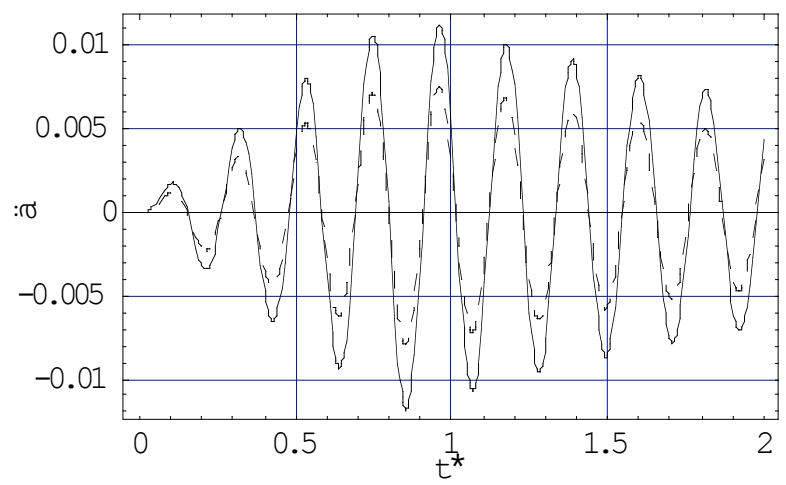

Fig. (19). Response of an FRP braced frame with $\mathrm{K}_{\mathrm{b}}^{*}=5$ and $\mathrm{K}_{\mathrm{c}}^{*}=10$ (stiff plate) under sinusoidal loading.

In Fig. (20) one can see the response of the same frame with a soft-plate FRP bracing system and stiffness ratios $\mathrm{K}_{\mathrm{b}}^{*}=5, \mathrm{~K}_{\mathrm{c}}^{*}=5$ under sinusoidal loading. 


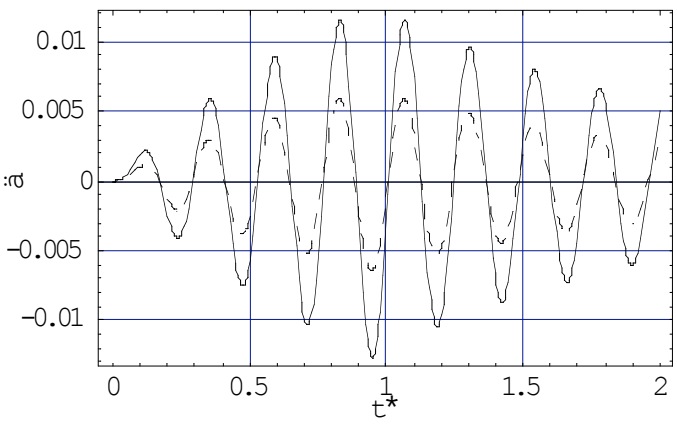

Fig. (20). Response of an FRP braced frame with $\mathrm{K}_{\mathrm{b}}^{*}=5$ and $\mathrm{K}_{\mathrm{c}}^{*}=5$ (soft plate) under sinusoidal loading.

Comparing the responses of the braced systems shown in Figs. (18) to (20), it can be seen that the maximum amplitude $\delta_{1}$ of the frame is almost the same for both cases of stiff and soft FRP plates, while the rise in amplitudes is almost $15.5 \%$ for the FRP plate systems compared to the maximum amplitude $\delta_{1}$ of the conventionally braced frame. Nevertheless, the maximum axial force $\mathrm{N}_{\mathrm{br}}$ of the braces drops in absolute values almost $9.8 \%$ in the case of a stiff FRP plate and $13.6 \%$ in the case of a stiff FRP plate V-joint compared to the corresponding one of the conventionally braced frame.

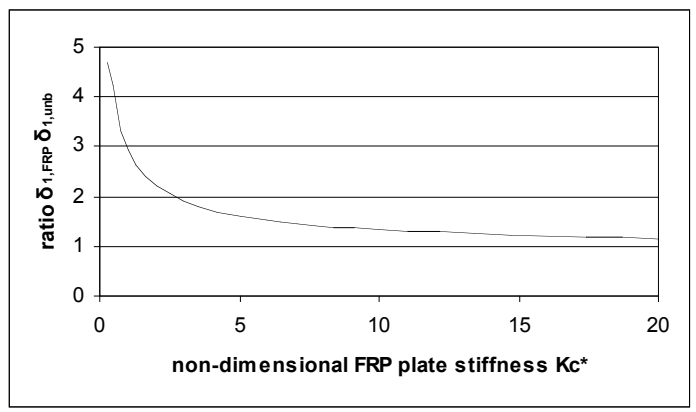

Fig. (21). Variation of the maximum amplitude ratio $\left(\delta_{1}\right)_{\mathrm{FRP}} /\left(\delta_{1}\right)_{\mathrm{cbr}}$ versus FRP-plate stiffness $\mathrm{K}_{\mathrm{c}}^{*}$.

In Fig. (21) one can see the variation of the amplitude ratio $\left(\delta_{1}\right)_{\mathrm{FRP}} /\left(\delta_{1}\right)_{\mathrm{cbr}}$ of the maximum responses of the FRP and the conventionally braced frames under step loading for various values of the non-dimensional FRP-plate stiffness $\mathrm{K}_{\mathrm{c}}^{*}$. From this figure, one can see that as the stiffness of the FRP plate rises, the corresponding amplitude ratio $\left(\delta_{1}\right)_{\mathrm{FRP}} /\left(\delta_{1}\right)_{\mathrm{cbr}}$ drops significantly. In Fig. (22), the variation of the braces axial force ratio $\mathrm{N}_{\mathrm{FRP}} / \mathrm{N}_{\mathrm{cbr}}$ for FRP and conventionally braced frames under step loading is plotted for various values of the non-dimensional FRP-plate stiffness $\mathrm{K}_{\mathrm{c}}^{*}$.

From Fig. (22) one can see that as the FRP plate becomes softer, the axial force acting in the braces drops rapidly. The same behavior is also encountered for half-sine loading.

\section{SUMMARY AND CONCLUSIONS}

In this study, an advanced $\mathrm{V}$-joint system for steel frames with FRP composite materials is presented. The main feature of this joining technique is that since FRPs are highly dissipative materials, the proposed system acts as an internal damping system dissipating rapidly an external dynamic

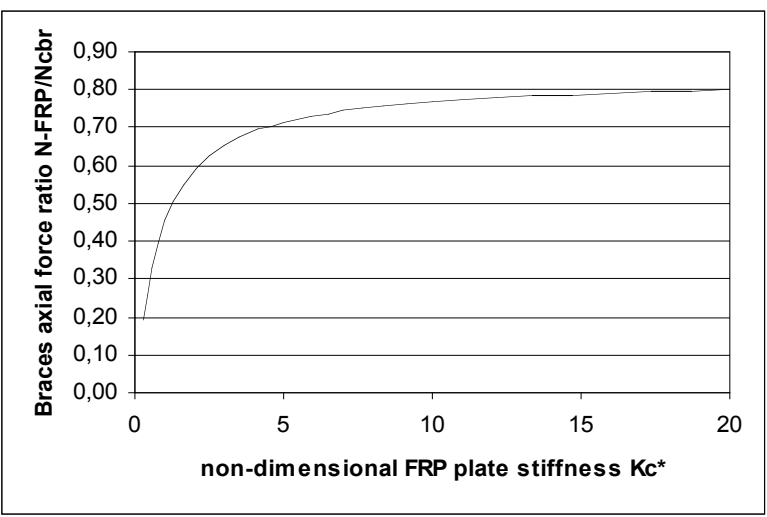

Fig. (22). Variation of the braces axial force ratio $\mathrm{N}_{\mathrm{br}, \mathrm{FRP}} / \mathrm{N}_{\mathrm{br}, \mathrm{cbr}}$ versus FRP-plate stiffness $\mathrm{K}_{\mathrm{c}}^{*}$.

excitation with finite duration. At this stage of research, it is assumed linear damping for the FRP plate and although this is a simplification, useful results for the dynamical behavior of the system are obtained. Moreover, the stiffness and damping properties of the FRP material can be tailored to fulfill design needs. Nonlinearities and temperature effects have not been considered in this investigation but are currently under research by developing full-scale experimental models.

The most important conclusions that can be drawn from this study are:

- The proposed joint acts as an internal damping system with high dissipation of energy due to the FRP material properties.

- The FRP plate is subjected purely to shearing membrane forces that are transferred to the braces.

- As the shear stiffness of the FRP plate decreases, the axial force acting onto the braces drops significantly.

- The presence of an FRP V-joint in a steel frame bracing leads to longer fundamental periods and higher total amplitudes for the structure.

- This effect is more pronounced in soft FRP joint systems, while in stiff joints the increase of period and amplitude is lower.

- Since the stiffness and damping properties of FRP materials can be tailored, the proposed joining technique can be employed to favorably alter the dynamical characteristics of conventional V-braced frames.

\section{REFERENCES}

[1] Eurocode 3, Design of Steel Structures, Part 1.1 General Rules and Rules for Buildings, European Committee for Standardization, Brussels, 2004.

[2] AISC, Seismic Provisions for Structural Steel Buildings, American Institute of Steel Construction, Chicago, IL, 2005.

[3] J. W. Berman and M. Bruneau, "Experimental and analytical investigation of tubular links for eccentrically braced frames". Engineering Structures, vol. 29, pp. 1929-1938, 2007.

[4] M. Dicleli and A. Mehta, "Seismic performance of chevron braced steel frames with and without viscous fluid dampers as a function of ground motion and damper characteristics", Journal of Constructional Steel Research, vol. 63, pp. 1102-1115, 2007. 
[5] M. Dicleli and A. Mehta, "Seismic response of a single storey innovative steel frame system", in Proceedings of Earthquake resistant engineering structures, Trans Wessex Institute, UK, 2005, pp. 259-267.

[6] J. C. Wilson and M. J. Wesolowsky, "Shape memory alloys for seismic response modification: A state-of-the-art review", Earthquake Spectra, vol. 21, no. 2, pp. 569-601, 2005.

[7] A. S. Pall and C. Marsh, "Response of friction damped braced frames", Journal of the Structural Division, ASCE, vol. 108(ST6), pp. 1313-1323, 1982.

[8] M. Martinez-Rodrigo and M. L. Romero, "An optimum retrofit strategy for moment resisting frames with nonlinear viscous dampers for seismic applications", Engineering Structures, vol. 25, no. 7, pp. 913-925, 2003.

[9] F. Bartera and R. Giaccetti, "Steel dissipating braces for upgrading existing building frames", Journal of Constructional Steel Research, vol. 60, pp. 751-769, 2004.
[10] J. R. Vinson and R. L. Sierakowski, The behavior of structures composed of composite materials, The Netherlands: Martinus Nijhoff, 1987.

[11] W. Flügge, Viscoelasticity, London: Bleisdell Publ. Co., 1967.

[12] A. C. Ugural and S. K. Fenster, Advanced strength and applied elasticity, SI ver, New York: Elsevier Sci Publ, 1984.

[13] G. B. Warburton, The dynamical behaviour of structures, London: Pergamon Press, 1976.

[14] C. T. Sun, J. K. Wu and R. F. Gibson, "Prediction of material damping of laminated polymer matrix composites", Journal of Materials Science, vol. 22, pp. 1006-1012, 1987.

[15] J. L. Sullivan, "Creep and physical aging of composites", Composites Science \& Technology, vol. 30, pp. 207-232, 1990.

[16] C. W. Bert, "Composite Materials: A survey of the damping capacity of fiber reinforced composites", in Proceedings of Damping Applications for Vibration Control, ASME-AMD-38, 1980, pp. 53-63.

(C) Ioannis G. Raftoyiannis; Licensee Bentham Open.

This is an open access article distributed under the terms of the Creative Commons Attribution License (http://creativecommons.org/licenses/by/2.5/), which permits unrestrictive use, distribution, and reproduction in any medium, provided the original work is properly cited. 